\title{
INCORPORACIÓN DE INULINA Y UN COMPLEJO ENZIMÁTICO EN LA RACIÓN ALIMENTICIA DE TERNEROS LACTANTES HOLSTEIN EN CRIANZA INTENSIVA
}

\author{
INCORPORATION OF INULIN AND AN ENZYMATIC COMPLEX INTO THE DIET OF \\ UNWEANED CALVES
}

${ }^{1}$ José Clavo M., ${ }^{2}$ José M. Almeyda M. y ${ }^{3}$ Erickson A. Ruíz F.

\begin{abstract}
Resumen
El presente ensayo se llevó a cabo en el establo de la Universidad Nacional Agraria La Molina, con el objetivo de evaluar los efectos de la incorporación de inulina y un complejo enzimático en la ración de terneros lactantes de raza Holstein en un periodo de destete de 56 días. Se utilizaron 20 terneros distribuidos en dos grupos: 1) Control: alimentados con leche entera y concentrado y, 2) Experimental: alimentados con leche entera y concentrado conteniendo inulina y un complejo enzimático. Para analizar los resultados de ganancia de peso, incremento de talla, consumo de alimento y conversión alimenticia; se utilizó el diseño completamente al azar y para evaluar los casos gastrointestinales y neumonías se usó la prueba de Chi-cuadrado. Los resultados fueron: ganancias de peso de 22,7 y 27,8 Kg. para el testigo y experimental respectivamente, no encontrándose diferencias significativas; incremento de talla de 7,6 y 9,8 cm. para el testigo y experimental respectivamente, siendo las diferencias significativas. Respecto al consumo de concentrado y ración total; en materia seca, el grupo experimental registró 23,9 y 47,6 Kg. respectivamente siendo significativamente superior al grupo testigo, que consumieron 19,7 y 43,1 Kg. respectivamente. Valores de 1,89 y 1,71 de conversión alimenticia se encontró para los grupos testigo y experimental respectivamente, no encontrándose diferencias significativas. En el aspecto sanitario se registró mayores casos de disturbios gastrointestinales y neumonías en los terneros del grupo testigo frente al experimental, siendo las diferencias significativas. El mérito económico calculado fue 17,59 y 13,89 para el testigo y experimental respectivamente. Como conclusión del estudio se puede inferir que la incorporación de inulina y complejo enzimático como aditivo no nutricional en el concentrado para terneros lactantes, permite mejorar el consumo de alimento y el incremento de talla así como disminuir la incidencia de disturbios gastrointestinales y neumonías.
\end{abstract}

Palabras claves: Inulina, ganancia de peso, incremento de talla, consumo de alimento y conversión alimenticia.

\section{Summary}

The present experiment took place in the dairy barn of La Molina National Agrarian University, with the aim of evaluate the effects of the incorporation of inulin and an enzyme complex in the ration of nurslings calves of Holstein breed in a period of weaning of 56 days. Twenty calves were used on two groups: 1) Control: fed with whole milk and concentrate, and 2) Experimental: fed with whole milk and concentrate containing inulin and enzyme complex. To analyze the results of weight gain, height increase, feed intake and feed conversion; was used completely randomized design to evaluate gastrointestinal and pneumonia cases we used the Chi-square test. The results were: weigth gain 22.7 and 27.8 $\mathrm{kg}$ for the control and experimental respectively, without significant differences; height increase of 7.6 and $9.8 \mathrm{~cm}$. for the control and experimental respectively, with significant differences. Regarding the consumption of concentrate and total ration: dry matter, the experimental group showed 23.9 and $47.6 \mathrm{~kg}$ respectively, being significantly higher than the control group, which consumed 19.7 and $43.1 \mathrm{~kg}$ respectively. Values of 1.89 and 1.71 in feed conversions were found for the experimental and control groups respectively, without significant differences. In the health aspect was recorder more cases of gastrointestinal disturbances and pneumonia in calves of the control group versus experimental group with significant differences. The economic merit calculated was 17.59 and 13.89 for the control and experimental group respectively. As a conclusion of this study if can inferred that the addition of inulin and enzyme complex like a not nutritional additive in the concentrate for nursling calves improves feed intake and height increase and decreases the incidence of pneumonia gastrointestinal disturbances.

Key words: inulin, height increase, weight gain, feed intake, feed convertion.

\section{Introducción}

La recría de terneros es una actividad clave dentro de la crianza de vacunos para producción de leche siendo el periodo más crítico desde el nacimiento hasta el destete con altos índices de mortalidad, observándose que la resistencia a enfermedades como diarreas y neumonías es

\footnotetext{
${ }^{1}$ Universidad Nacional Agraria La Molina, Lima, Perú.

${ }^{2}$ Universidad Nacional Agraria La Molina, Lima, Perú. E-mail: jalmeyda@lamolina.edu.pe

${ }^{3}$ Universidad Nacional Agraria La Molina, Lima, Perú. E-mail:ericksonruizf@lamolina.edu.pe
} 
mínima, por ello los sistemas de manejo y alimentación están orientados a una mejor nutrición, una reducción de problemas sanitarios y a una mejor respuesta a la crianza. En este sentido Bacha (1999) indica que la crianza de bovinos jóvenes representa uno de los mayores problemas en las explotaciones comerciales, puesto que es en ese momento cuando se deben sentar las bases para un correcto crecimiento pero a la vez, es el periodo donde más delicados son.

Casas (2006) considera que los objetivos de un sistema de crianza de terneros son: tener una mortalidad inferior a $5 \%$ para lograr ganancias de peso de 700 gr/día y conseguir animales con más de $80 \mathrm{~kg}$ de peso al destete. En el mismo sentido Heinrichs (1999) considera lograr pesos adecuados a los 28 días en un rango de 60,4 a 70,4 $\mathrm{kg}$ y Hoffman (1997) recomienda como muy buenos indicadores de medidas corporales para terneras lactantes de raza Holstein: pesos de 42, 63, 84 y $110 \mathrm{~kg}$ y una altura a la cruz de $75,81,86$ y $92 \mathrm{~cm}$ al nacimiento, 1, 2 y 3 meses de edad respectivamente con ganancias de peso de 700 a 840 g/día. Del mismo modo Wattiaux (1997) indica que el manejo de terneras puede ser considerado exitoso cuando se alcanza menos de $5 \%$ de mortalidad y una tasa de crecimiento de 750 gr/día para que cuando lleguen al primer parto logren un adecuado peso corporal. Además menciona que tasas menores a 340 gr/día significa un crecimiento lento por lo que inmediatamente se debe revisar y mejorar sus alimentación, instalaciones y cuidados de la salud. El mismo autor menciona que el objetivo de todo programa de alimentación de terneras previo al destete no es el de maximizar la ganancia de peso corporal, pero si el de asegurar una buena salud, un buen crecimiento esquelético y un adecuado nivel de consumo de iniciador para promover el desarrollo ruminal. Por ello Heinrichs (1999) considera que los terneros Holstein a la edad de 56 días deben lograr una talla en un rango de 85,1 y $89,4 \mathrm{~cm}$ para considerarse que se ha logrado un buen crecimiento. Para reforzar el concepto; Heinrichs (1999) y Campabadal, (2000) recomiendan que los pre-iniciadores deben ser alimentos de alta calidad, caracterizados por tener diferentes tamaños, consistencia y forma de partículas y si se puede adicionar prebióticos, como la inulina y oligofructuosa, se espera conseguir dos efectos directos: La modificación de la composición de la flora microbial intestinal, promoviendo el crecimiento de bacterias benéficas y la conversión de inulina en metabolitos los mismos que al ser liberadas en el medio ambiente intestinal, acidifican el $\mathrm{pH}$ del contenido intestinal, limitando el crecimiento de bacterias patógenas. Asimismo como efecto indirecto, tanto la inulina como la oligofructosa son absorbidos como metabolitos en la sangre, lo que les permite interactuar en los diversos procesos fisiológicos, mejorando la salud intestinal y la absorción de calcio (Orafti, 2007).

El presente trabajo de investigación tuvo como objetivo evaluar el efecto de la inulina y un complejo enzimático (amilasa, celulasa y xilanasa) incorporado en la dieta alimenticia de terneros lactantes de raza
Holstein, sobre la ganancia de peso, incremento de talla, consumo de alimento, conversión alimenticia, disturbios gastroentéricos, neumonías y merito económico bajo un sistema de crianza intensiva.

\section{Materiales y métodos}

El trabajo de investigación se llevó a cabo durante los meses de mayo a octubre del 2008 en las instalaciones del establo lechero de La Universidad Nacional Agraria La Molina, con una duración total de 56 días utilizándose 20 terneros de raza Holstein provenientes de madres multíparas de un día de nacido, agrupados aleatoriamente en dos grupos de 10 terneros cada uno con 5 hembras y 5 machos. Luego de la asistencia sanitaria después del nacimiento, fueron identificados, pesados, tallados y alojados en cunas individuales donde permanecieron hasta el destete. El programa sanitario practicado fue preventivo, y en casos extremos se aplicó tratamientos individuales de naturaleza curativa. Los casos de diarreas fueron tratados mediante antibióticos (sulfadoxicina y trimetropin), protector de mucosa y suero electrolítico mientras que para los casos de neumonías se trataron con antibióticos (oxitretraciclina y enrofloxacina), antinflamatorio (dexametasona) y aceite alcanforado. Los terneros fueron alojados en cunas individuales de madera, con área de sombra y equipados con comederos y bebederos individuales de plástico, y material de cama cambiable. Los materiales e insumos utilizados durante el manejo fueron: balanza de plataforma de $250 \mathrm{Kg}$. con cajón de pesada, hipómetro graduado en $\mathrm{cm}$., equipo tatuador, balanza con capacidad para $5 \mathrm{Kg}$., baldes de plástico de 4 litros de capacidad, antibióticos y desinfectantes además de termómetro rectal y libreta de apuntes. Se consideraron dos grupos: control (T-1): Terneros alimentados con una dieta alimenticia conteniendo leche entera y alimento balanceado de inicio; y experimental (T-2): Dieta igual al anterior con alimento balanceado conteniendo la mezcla de la inulina $(0.1 \%)$ y complejo enzimático $(0.1 \%)$. Ambas dietas proporcionadas de acuerdo al programa establecido por el establo, la cual se describe en la tabla 1:

Tabla 1. Programa de alimentación de terneros del establo.

\begin{tabular}{cccc}
\hline $\begin{array}{c}\text { Edad } \\
(\text { días })\end{array}$ & $\begin{array}{c}\text { Cantidad } \\
\text { suministrada } \\
\text { diariamente (1/d) }\end{array}$ & Concentrado & Agua \\
\hline Primer & 41 de calostro & --- & --- \\
ordeño & 4 LT & --- & --- \\
$1-4$ & $4 \mathrm{LE}$ & --- & --- \\
$5-6$ & $4 \mathrm{LE}$ & Ad libitum & Restringido \\
$7-56$ & & & \\
\hline
\end{tabular}

Fuente: Elaboración propia

Donde:

Calostro: Leche del primer ordeño

L/d: Litros /día

L: Litros

LT: Leche de transición

LE: Leche entera 
La ración de concentrado fue analizada en el Laboratorio de Evaluación Nutricional de Alimentos (LENA) de la Universidad Nacional Agraria La Molina; la misma que se observa en la tabla 2.

Tabla 2. Análisis químico proximal del concentrado de inicio (polvo).

\begin{tabular}{lcc}
\hline Componentes & $\begin{array}{c}\text { \% Base } \\
\text { Fresca }\end{array}$ & $\begin{array}{c}\% \text { Base } \\
\text { Seca }\end{array}$ \\
\hline a. Materia Seca, \% & 88,11 & 100,00 \\
b. Proteína Total (NX6.25),\% & 18,62 & 21,13 \\
c. Extracto Etéreo, \% & 6,76 & 7,67 \\
d. Fibra Cruda, \% & 4,27 & 4,85 \\
e. Ceniza,\% & 4,89 & 5,55 \\
f. Extracto Libre de Nitrógeno, \% & 53,57 & 60,80 \\
g. NDT, \% & 73,25 & 83,13
\end{tabular}

Fuente: Laboratorio de Evaluación Nutricional de Alimentos de la UNALM, 2008

Ambos grupos recibieron iguales protocolos de manejo y sanidad; realizándose controles semanales de pesos y talla; siendo el reparto y pesado de consumo y residuo de alimento diariamente, a partir del cual se determinó la conversión alimenticia.

Los resultados de pesos, tallas, consumo de alimento y conversión alimenticia; fueron evaluados a través del análisis de variancia del Diseño Completamente al Azar (DCA).

Para la determinación del mérito económico se utilizó la relación del costo total (alimentación, sanidad y mano de obra) entre la respuesta en ganancia de peso vivo, y para la evaluación de disturbios gastrointestinales y neumónicos se utilizó la prueba de Chi-cuadrado:

$$
\chi^{2}=\sum_{i=1}^{k} \frac{\left(O_{i}-E_{i}\right)^{2}}{E_{i}}
$$

Donde:

$\mathrm{O}_{\mathrm{i}}=$ Frecuencia observada

$\mathrm{E}_{\mathrm{i}}=$ Frecuencia esperada.

\section{Resultados y discusión}

El peso promedio al nacimiento de los terneros del grupo control fue de $39,8 \pm 4,9 \mathrm{Kg}$. y del grupo experimental fue de 43,7 $\pm 5,1 \mathrm{Kg}$, al realizar la comparación de medias no se encontró diferencias estadísticas significativas entre los dos grupos $(\mathrm{P}>0,05)$. Estos pesos fueron similares a lo indicado por Hoffman (1997).

Los pesos promedios evaluados a la cuarta semana (28 días) del experimento, no mostraron diferencias estadísticas significativas $(\mathrm{P}>0,05)$, siendo los valores 47,5 y $53,6 \mathrm{Kg}$. para los tratamientos 1 y 2 , respectivamente; éstos valores fueron inferiores al rango de 60,4 y 70,4 kg recomendado a ésta edad para terneros Holstein por Heinrichs (1999), así como lo mencionado por Hoffman (1997) quien indica un peso de $63 \mathrm{~kg}$. En la tabla 3 se indica los valores de pesos y tallas semanales desde el nacimiento hasta los 56 días, mientras que en las figuras 1 y 2 se observa la evolución de los pesos y tallas respectivamente de los grupos experimentales.

Tabla 3. Promedios y desviaciones estándar de pesos vivos y tallas semanales por grupos experimentales.

\begin{tabular}{lllll}
\hline \multirow{2}{*}{$\begin{array}{l}\text { Edad } \\
\text { (días) }\end{array}$} & \multicolumn{2}{c}{ Control (T-1) } & \multicolumn{2}{c}{ Experimental (T-2) } \\
\hline Nacimiento & $39,8^{\mathrm{a}} \pm 4,9$ & $76,3^{\mathrm{a}} \pm 3,7$ & $43,7^{\mathrm{a}} \pm 5,1$ & $80,1^{\mathrm{b}} \pm 1,9$ \\
7 & $41,2^{\mathrm{a}} \pm 5,9$ & $76,3^{\mathrm{a}} \pm 3,3$ & $46,4^{\mathrm{a}} \pm 5,1$ & $80,1^{\mathrm{b}} \pm 3,3$ \\
14 & $42,5^{\mathrm{a}} \pm 6,2$ & $77,5^{\mathrm{a}} \pm 3,6$ & $48,4^{\mathrm{a}} \pm 4,2$ & $81,1^{\mathrm{b}} \pm 3,4$ \\
21 & $45,1^{\mathrm{a}} \pm 6,7$ & $78,0^{\mathrm{a}} \pm 3,9$ & $51,0^{\mathrm{a}} \pm 5,0$ & $82,1^{\mathrm{b}} \pm 2,3$ \\
28 & $47,5^{\mathrm{a}} \pm 6,9$ & $78,8^{\mathrm{a}} \pm 3,9$ & $53,6^{\mathrm{a}} \pm 5,5$ & $82,7^{\mathrm{b}} \pm 2,3$ \\
35 & $49,5^{\mathrm{a}} \pm 7,0$ & $80,1^{\mathrm{a}} \pm 4,4$ & $59,0^{\mathrm{a}} \pm 4,8$ & $84,5^{\mathrm{b}} \pm 2,3$ \\
42 & $54,1^{\mathrm{a}} \pm 7,7$ & $81,2^{\mathrm{a}} \pm 4,2$ & $62,9^{\mathrm{a}} \pm 4,8$ & $85,4^{\mathrm{b}} \pm 2,0$ \\
49 & $59,1^{\mathrm{a}} \pm 9,2$ & $82,0^{\mathrm{a}} \pm 4,5$ & $67,0^{\mathrm{a}} \pm 4,2$ & $86,0^{\mathrm{b}} \pm 2,2$ \\
56 & $62,5^{\mathrm{a}} \pm 10,1$ & $81,2^{\mathrm{a}} \pm 4,5$ & $71,5^{\mathrm{a}} \pm 6,1$ & $87,2^{\mathrm{b}} \pm 2,3$ \\
\hline
\end{tabular}

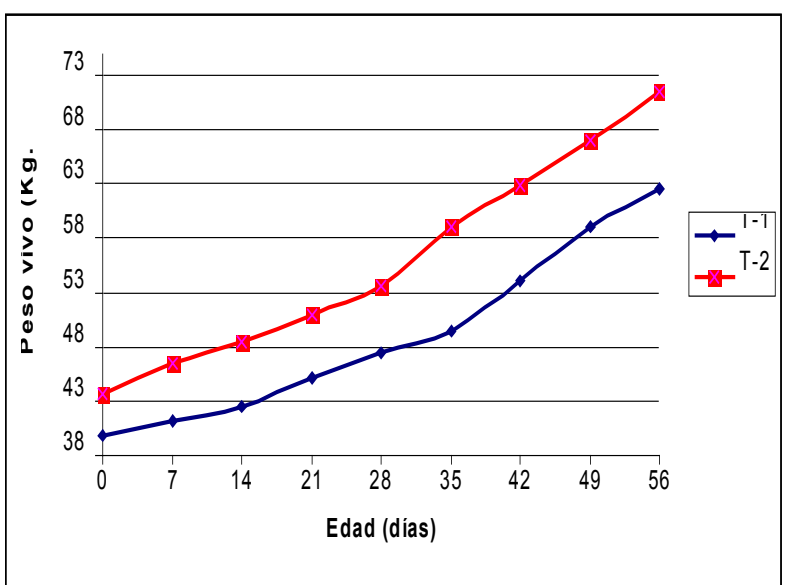

Figura 1. Evolución de los pesos vivos promedios semanales de los grupos experimentales evaluados.

Respecto a la talla, en el grupo experimental se observó una tendencia a un mayor ritmo de crecimiento comparado al grupo control durante el periodo lactante: La talla promedio al nacimiento fue de 76,3 $\pm 3,7$ y $80,1 \pm 5,1 \mathrm{~cm}$. para el grupo control y experimental respectivamente; no existiendo diferencias estadísticas significativas entre los dos grupos $(\mathrm{P}>0,05)$. Las tallas evaluadas a la cuarta semana (28 días) del experimento, mostraron diferencias estadísticas significativas en ambos grupos ( $\mathrm{P}$ $\leq 0,05)$ siendo de 78,8 y $82,7 \mathrm{~cm}$. para el grupo control y 
experimental, respectivamente. El valor de talla del grupo experimental se encuentra cerca del rango de 85,1 a 89,4 $\mathrm{cm}$ recomendado por Heinrichs (1999) para terneros de la raza Holstein. Como puede observarse, la evolución de la talla obtenida semanalmente, muestra una tendencia de mayor incremento en el grupo experimental frente al control.

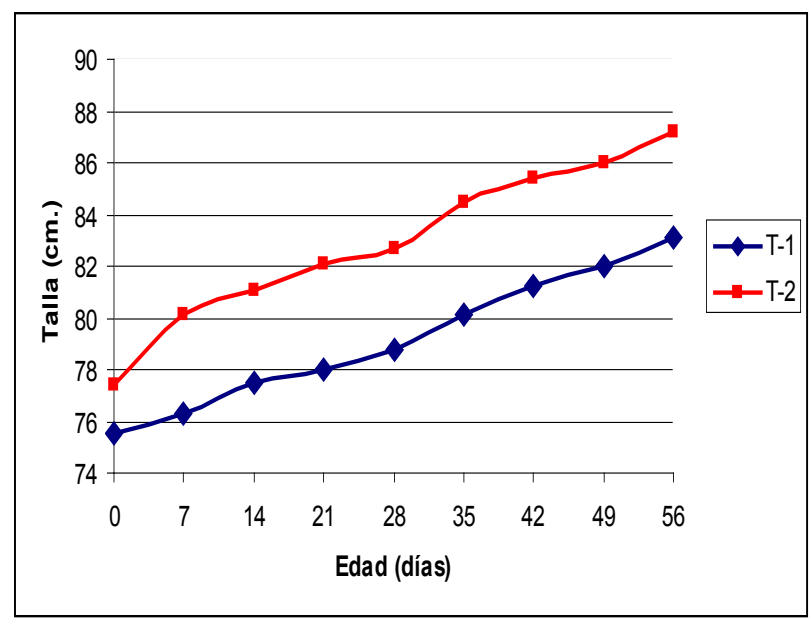

Figura 2. Evolución de las tallas acumuladas de terneros por tratamiento evaluado.

Respecto a los pesos promedios finales, fueron 62,5 y $71,5 \mathrm{Kg}$. para los tratamientos control y experimental respectivamente (tabla 4); no encontrándose diferencias estadísticas significativas entre ellos $(\mathrm{P}>0,05)$. En cuanto a las ganancias promedio de peso logrados fueron de 22,7 y $27,8 \mathrm{~kg}$. para el grupo control y experimental respectivamente, cuyas diferencias no fueron estadísticamente significativas $(\mathrm{P}>0,05)$. Los promedios de ganancias de pesos por animal y por día fueron 405,4 y 496,4 g/a/d para los grupos control y experimental respectivamente. Éstos resultados evidencian una incidencia estadística no significativa $(\mathrm{P}>0,05)$ entre ambos grupos.

De manera general, no hubo diferencias entre los pesos de los tratamientos evaluados, destacándose que los valores encontrados al destete de 56 días distan de los estándares de la raza Holstein, así como a lo recomendado por Casas (2006) y Hoffman (1997) quienes recomiendan valores de 80 y $74 \mathrm{~kg}$ respectivamente. Igualmente en lo uqe respecta a los incrementos de pesos diarios, los valores encontrados son inferiores a lo recomendado por Hoffman (1997) y Wattiaux (1997), quienes recomiendan indicadores de ganancias de 700 y $750 \mathrm{~g} /$ día respectivamente. Los índices encontrados significan una ganancia corporal lento en los animales, debido probablemente al sistema de alimentación practicado en el establo.

Respecto a la talla; los promedios finales, el incremento de talla total y diaria, y sus respectivas desviaciones estándar para los tratamientos evaluados (tabla 4); se observa que la talla final a los 56 días tuvo un promedio de 83,1 y 87,2 $\mathrm{cm}$. para el grupo control y experimental respectivamente, encontrándose diferencias estadísticamente significativas entre ellas $(\mathrm{P} \leq 0,05)$, donde se nota que el valor del grupo experimental se encuentra dentro del rango de 85,1 y $89,4 \mathrm{~cm}$ recomendado por Heinrichs (1999), para la raza Holstein. La misma tabla muestra los promedios de incremento de tallas totales, los cuales fueron de 7,6 y $9,8 \mathrm{~cm}$. para el grupo control y experimental respectivamente, existiendo diferencias estadísticamente significativas entre los valores $(\mathrm{P} \leq 0,05)$, del mismo modo, los promedios de incremento de tallas por animal y por día fueron 0,14 y $0,18 \mathrm{~cm} . / \mathrm{a} / \mathrm{d}$ para $\mathrm{los}$ tratamientos control y experimental respectivamente, resultados que evidencian una superioridad de incidencia estadística significativa a favor del grupo experimental; en este sentido este resultado concuerda con el objetivo planteado por Wattiaux (1997), quien indica que todo programa de alimentación de terneras previo al destete no es el de maximizar la ganancia corporal pero si el de asegurar una buena salud, un buen crecimiento esquelético y un adecuado nivel de consumo de iniciador para promover el desarrollo ruminal. Igualmente concuerda con lo indicado por Bacha (1999), quien recomienda que la etapa lactante es el momento para sentar las bases para un crecimiento correcto de las futuras terneras. Por lo indicado se puede inferir que la incorporación de inulina y el complejo enzimático en la ración alimenticia del grupo experimental tuvo un efecto significativo sobre una mayor eficiencia en la digestión de la proteína del alimento generando una mayor absorción de aminoácidos así como de calcio lo cual explicaría el mayor crecimiento de las terneras del grupo experimental.

Tabla 4. Promedios de pesos y tallas finales, ganancias de pesos total incremento de talla total y diario por tratamiento evaluado.

\begin{tabular}{lcc}
\hline \multirow{2}{*}{ Parámetros } & \multicolumn{2}{c}{ Tratamientos } \\
& Control (T-1) & Experimental (T-2) \\
\hline Peso final (kg) & $62,5^{\mathrm{a}} \pm 10,1$ & $71,5^{\mathrm{a}} \pm 6,1$ \\
GPPT (kg) & $22,7^{\mathrm{a}} \pm 8,2$ & $27,8^{\mathrm{a}} \pm 4,2$ \\
GPPD (g/d) & $405,4^{\mathrm{a}} \pm 0,2$ & $496,4^{\mathrm{a}} \pm 0,1$ \\
Talla final, (cm) & $83,1^{\mathrm{a}} \pm 4,5$ & $87,2^{\mathrm{b}} \pm 2,3$ \\
IPTT, (cm) & $7,6^{\mathrm{a}} \pm 2,5$ & $9,8^{\mathrm{b}} \pm 1,2$ \\
IPTD, (cm $/ \mathrm{d})$ & $0,14^{\mathrm{a}} \pm 0,1$ & $0,18^{\mathrm{b}} \pm 0,2$ \\
\hline
\end{tabular}

$a, a$ No existen diferencias significativas $(P>0,05)$

a,b Existen diferencias significativas $(\mathrm{P} \leq 0,05)$

GPPT $=$ Ganancia promedio de peso total promedio de peso diario

IPTT $=$ Incremento promedio de talla total GPPD $=$ Ganancia promedio de talla diaria.

Por otro lado, en lo que respecta a los problemas gastroentéricos y neumónicos los resultados difieren de manera significativa encontrándose mayores casos en 
los terneros del grupo control. Los resultados registraron 8 y 3 casos de disturbios gastroentéricos y 4 y 1 casos de neumonías para el grupo control y experimental respectivamente. Al análisis de los datos mediante la prueba de Chi-cuadrado se encontró diferencias estadísticas significativas entre ellas $(\mathrm{P} \leq 0,05)$, esto debido probablemente a que los terneros del grupo control necesitaron en promedio más días de tratamientos para su recuperación comparado a los del grupo experimental que estuvieron estresados debido al tratamiento sanitario a que fueron sometidos, lo cual pudo afectar su apetito y consecuentemente en la reducción de consumo de alimentos así como a una disminución en su inmunidad. También puede deberse a que la inulina y el complejo enzimático incluido en la ración de los terneros del grupo experimental favorecieron la colonización y la multiplicación de microorganismos benéficos y limitaron el desarrollo de bacterias patógenas a nivel del colon, de esta manera previno causas de diarreas y promovió el mejor funcionamiento del tracto digestivo. Estos resultados concuerdan con lo mencionado por Campabadal (2001) quien afirma que se puede adicionar prebióticos a la ración de terneros como inulina y oligofructuosa cuyos efectos directos es que modifican la flora microbial intestinal promoviendo el crecimiento de bacterias benéficas, además de acidificar el $\mathrm{pH}$ del contenido intestinal limitando el crecimiento de otros grupos de bacterias patógenas. En el mismo sentido Orafti (2007) indica que la adición de inulina en la ración es absorbida como metabolitos lo que le permite interactuar en los procesos fisiológicos, mejorando la salud intestinal y la absorción de calcio en los terneros.

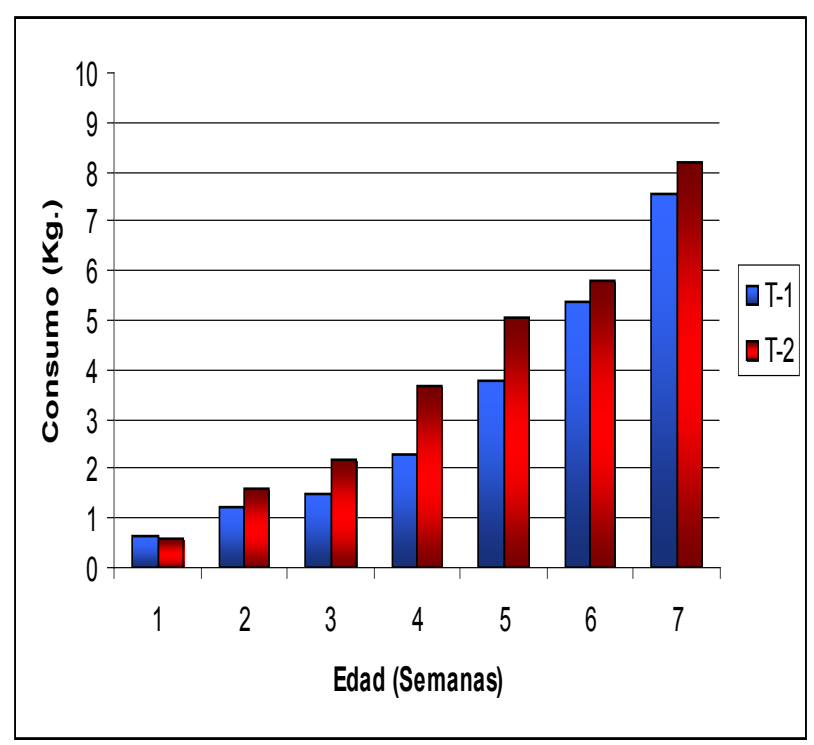

Figura 3. Consumo promedio de concentrado semanal por tratamiento evaluado.

En la tabla 5 se presenta la conversión alimenticia promedio basada en el consumo total de la dieta (leche entera y alimento concentrado de inicio) y la ganancia de peso promedio, fue de 1,89 y 1,71 para el grupo control y experimental respectivamente, al realizar el ajuste mediante arco seno igualmente no hubo diferencias estadísticas significativas $(\mathrm{P}>0,05)$ entre ambos grupos.

Tabla 5. Consumo de alimento por tratamiento evaluado.

\begin{tabular}{|c|c|c|}
\hline \multirow[b]{2}{*}{ Parámetros } & \multicolumn{2}{|c|}{ Tratamientos } \\
\hline & $\begin{array}{l}\text { Control } \\
\text { (T-1) }\end{array}$ & $\begin{array}{c}\text { Experimental } \\
(\mathrm{T}-2)\end{array}$ \\
\hline $\begin{array}{l}\text { Consumo alimento } \\
\text { líquido (Kg. MS) }\end{array}$ & $23,4^{\mathrm{a}} \pm 0,7$ & $23,5^{\mathrm{a}} \pm 0,4$ \\
\hline $\begin{array}{l}\text { Consumo concentrado } \\
\text { (Kg. MS) }\end{array}$ & $19,7^{\mathrm{a}} \pm 6,4$ & $23,9^{b} \pm 6,3$ \\
\hline $\begin{array}{l}\text { Consumo promedio total } \\
\text { de alimento }(\mathrm{Kg} . \mathrm{MS})\end{array}$ & $43,1^{a} \pm 6,6$ & $47,4^{b} \pm 6,4$ \\
\hline Ganancia total P.V. (Kg.) & 22,7 & 27,8 \\
\hline C.A. de la dieta & $1,89^{\mathrm{a}} \pm 0,9$ & $1,71^{\mathrm{a}} \pm 0,3$ \\
\hline
\end{tabular}

En la tabla 6 se presenta la evaluación económica según el tipo de tratamiento. El mérito económico fue 17,59 y 13,89 para el grupo control y experimental, respectivamente; siendo más eficiente la dieta que contenía la inulina y complejo enzimático en $21 \%$ respecto a la dieta del grupo control. En este estudio se observa además un menor costo de la ración promedio, siendo de S/. 9,27 para el grupo control y de S/. 8,14 para el grupo experimental. Los resultados indican que se estaría obteniendo un beneficio económico promedio por ternero destetado de $\mathrm{S} / .13,33$ a favor del grupo experimental, comparado al grupo control.

Tabla 6. Evaluación económica según el tipo de tratamiento evaluado.

\begin{tabular}{lll}
\hline \multirow{2}{*}{ Parámetros } & \multicolumn{2}{c}{ Tratamientos } \\
\cline { 2 - 3 } & \multicolumn{1}{c}{$\begin{array}{c}\text { Control } \\
\text { (T-1) }\end{array}$} & $\begin{array}{c}\text { Experimental } \\
\text { (T-2) }\end{array}$ \\
\hline Consumo kg/a/período & 43,1 & 47,4 \\
Ganancia total P.V. kg & 22,7 & 27,8 \\
Costo total de alimentación & 399,34 & $386,01^{*}$ \\
Conversión alimenticia & 1,89 & 1,71 \\
Mérito económico & 17,59 & 13,89 \\
Costo ración/kg. S/. & 9,27 & 8,14 \\
\hline
\end{tabular}

* Se ha estimado un valor cero para la inulina y el complejo enzimático

\section{Conclusiones}

La incorporación de inulina y el complejo enzimático en el concentrado de inicio del grupo experimental no tuvo efecto en la ganancia de peso, pero sí incidió en el lobro de un mayor incremento de talla siendo esto lo más resaltante ya que la altura a la cruz refleja el crecimiento de su cuerpo (crecimiento esquelético) que es lo que 
interesa en la crianza de terneras ya que una adecuada tasa de crecimiento influye considerablemente en la edad de la pubertad y por consiguiente en la edad al primer parto. Se observó también un mayor consumo promedio de concentrado y de la ración total del alimento lo cual es beneficioso ya que otro de los objetivos de un programa de alimentación es lograr un buen nivel de consumo de iniciador para promover el desarrollo ruminal a temprana edad. Finalmente en el aspecto sanitario se registró un menor número de casos de disturbios gastrointestinales y neumonías siendo este aspecto igualmente muy importante por tratarse de las enfermedades más comunes de la cría de terneros en este sentido todo ganadero sabe que terneras no saludables pierden su potencial de producción de leche en el futuro, crecen lentamente y requieren de un proceso de crianza más largo y consecuentemente con un mayor costo.

\section{Literatura citada}

Bacha. F., 1999. Nutrición del ternero neonato. XV Curso de Especialización. Avances en Nutrición y Alimentación Animal. Fundación Española para el Desarrollo de la Nutrición Animal FEDNA, Barcelona, España, 277-301 Nacoop, S.A. Madrid. URL disponible en: http://www. etsia.upm.es/fedna/capitulos/99CAP11.pdf [Consulta 15 junio del 2008]

Campabadal. 2001. Alimentación para terneras y novillas de reemplazo. Universidad de Costa Rica. Disponible en: http://www.feednet.ucr.ac.cr/bromatologia/rfagl.htm. [Consulta 15 junio del 2008].

Casas, M. 2006. Crianza de vaquillas: El futuro y el éxito de las lecherías. Chile.

Classen, H. L. 1993. Enzimas usadas en el alimento. Universidad de Saskatchewan. Saskatoon, Canadá. En: Avicultura profesional. Vol. $10 \mathrm{~N}^{\circ} 4$. Pp. 162-168

Heinrichs, A. J. 1999. Feeding the Newbom Dairy Calf. Special Circular 311. Collage of Agricultura and Cooperative Extension. Penn State.

Hoffman, P. C. 1997. Optimum body size of Holstein replacement heiferts. Journal of Animal Science. 75:836845.

Orafti. 2007. Inulin and Oligofructose are Valuable Pet Food Ingredients.

Wattiaux, M. A. 1999. Crianza de terneras-del nacimiento al destete - alimentando heno, concentrado y agua. Cap 30 Nutritivo. Instituto Babcock para el desarrollo y la Investigación Internacional de la lechería Reproducción y Selección genética. Disponible en: http:// babcock,cals.wisc.edu/spanish/de/dairy_essentials_spn spn.html. [Consulta 25 abril del 2008]. 